\title{
Developing a Tailored Implementation Action Plan for A Suicide Prevention Clinical Intervention in an Australian Mental Health Service: A Qualitative Study Using the EPIS Framework.
}

Isabel Zbukvic ( $\nabla$ isabelzbukvic@gmail.com )

The University of Melbourne - Parkville Campus: University of Melbourne https://orcid.org/0000-0002-6816-1199

Demee Rheinberger

Black Dog Institute, University of New South Wales

\section{Hannah Rosebrock}

Black Dog Institute, University of New South Wales

Jaclyn Lim

Black Dog Institute, University of New South Wales

Lauren McGillivray

Black Dog Institute, University of New South Wales

Katherine Mok

Black Dog Institute, University of New South Wales

Eve Stamate

Black Dog Institute

Katie McGill

Hunter New England Mental Health Services, University of Newcastle

Fiona Shand

Black Dog Institute, University of New South Wales

Michelle Torok

University of New South Wales

Joanna C Moullin

Curtin University

\section{Research}

Keywords: Suicide prevention, tailored implementation, EPIS, CAMS, mental health, qualitative, implementation, sustainment, evidence-based practice, determinants of practice

Posted Date: January 14th, 2021

DOI: https://doi.org/10.21203/rs.3.rs-142115/v1

License: (c) (i) This work is licensed under a Creative Commons Attribution 4.0 International License. Read Full License

Version of Record: A version of this preprint was published at Implementation Research and Practice on January 1st, 2022. See the published version at https://doi.org/10.1177/26334895211065786. 


\section{Abstract}

Background: Tailoring implementation strategies to local contexts is a promising approach to supporting implementation and sustainment of evidence-based practices in health settings. While there is increasing research on tailored implementation of mental health interventions, implementation research on suicide prevention interventions is limited. This study aimed to evaluate implementation and subsequently develop a tailored action plan to support implementation, sustainment and scale-up of an evidence-based suicide prevention intervention - Collaborative Assessment and Management of Suicidality (CAMS) - in an Australian public mental health service.

Methods: This study took place within a larger randomised stepped-wedge design suicide prevention trial. Approximately 150 mental health staff working within a regional and remote community Local Health District in Australia were trained in CAMS. Semi-structured interviews and focus groups with frontline staff and clinical leaders were conducted to examine barriers and facilitators to using CAMS. Data were analysed using a reflexive thematic analysis approach and mapped to the Exploration, Preparation, Implementation and Sustainment (EPIS) framework. This was followed by stakeholder engagement to design a tailored implementation action plan based on a 'tailored blueprint' methodology.

Results: A total of 22 barriers to implementing CAMS were identified. Based on the perceived impact on implementation fidelity and the feasibility of addressing identified barriers, six barriers were prioritised for addressing through an implementation plan. These barriers were mapped to evidence-based implementation strategies and, in collaboration with local health district staff, goals and actionable steps for each strategy were generated. This information was combined into a tailored implementation plan to support the sustainable use of CAMS as part of routine care within this mental health service.

Conclusions: This study provides an example of a collaborative approach to tailoring strategies for implementation on a large scale. Novel insights were obtained into the challenges of evaluating the implementation process and barriers to implementing an evidence-based suicide prevention treatment approach within a geographically large and varied mental health service in Australia.

Trial registration: This study was conducted as part of the LifeSpan suicide prevention trial. Trial registration for LifeSpan in Australia New Zealand Clinical Trials Register, ID: ACTRN12617000457347. Prospectively registered on 28 March 2017.

\section{Contributions To The Literature}

- This study outlines the process of using a collaborative stakeholder engagement approach to developing tailored implementation plans

- Using the Exploration Preparation Implementation Sustainment (EPIS) Framework, findings identify the barriers to and strategies for implementing evidence-based practice, specifically for a clinical suicide prevention intervention in a community mental health setting

- This is the first known study to use an implementation science framework to investigate the implementation of the clinical suicide prevention intervention (Collaborative Assessment and Management of Suicidality) within a community mental health setting

- This work highlights the challenges of conducting implementation research in a dynamic public health service

\section{Background}

Suicidal behaviour is a significant public health concern and can have profound and long-lasting effects on the mental health of individuals, families, and communities. In Australia, suicide is the leading cause of death for people aged 15-44 years, with the national suicide rate increasing over the last decade (1). Suicide prevention is a priority across the 
Australian health system, reflected in federal initiatives such as the National Mental Health and Suicide Prevention Plan and National Suicide Prevention Implementation Strategy $(2,3)$. Ensuring the public mental health workforce is equipped to deliver appropriate psychosocial interventions is central to early intervention and treatment for suicidality, as well as care after a suicide attempt. As such, access to appropriate psychosocial support is a key strategy in the emerging best practice multi-level approaches to suicide prevention (4).

Collaborative Assessment and Management of Suicidality (CAMS) is an evidence-based practice (EBP) designed to facilitate a collaborative approach to assessing and managing suicidality (5). Intended for use by mental health professionals, CAMS is one of a relatively limited number of psychological treatment approaches that specifically targets suicidal thoughts and behaviours. Several randomised controlled trials have demonstrated the efficacy of CAMS in reducing suicidal ideation, and there is promising evidence for its impact on reducing self-harm behaviour and suicide attempts (6-12). Developed by clinical researchers in the US, CAMS has been primarily tested in US healthcare settings including inpatient and outpatient care. Notably, there is currently no known research on CAMS in the Australian public health system. Although some research on CAMS has included fidelity monitoring (13), there is also no known research specifically on the implementation of CAMS in a naturalistic setting outside a clinical trial.

There is a growing understanding that complex settings such as mental health services need multiple implementation strategies and support to introduce and integrate a EBP. One approach encouraged in implementation literature is tailoring strategies to the local implementation context (14) to encourage innovation-fit (15). This approach is based on the concept that to be effective, implementation strategies should be selected based on local practice barriers and tailored to the specific contexts in which they will be implemented to improve uptake (16). Although tailored implementation has shown promising outcomes across a range of health contexts, including in mental health service delivery (17), research specifically on the implementation of suicide prevention initiatives is scarce. A recent review of multilevel approaches to suicide prevention showed less than $10 \%$ of published research included a process or implementation evaluation (18). Understanding how to effectively implement suicide prevention EBPs is key to ensuring they are effectively embedded in routine care, so that services can help to reduce the devastating impact of suicide.

The aim of this study was to develop a tailored action plan for implementing CAMS in an Australian mental health service. A stakeholder engagement approach was used based on the 'tailored blueprint' methodology developed and trialled by Lewis and colleagues (19), along with the Exploration, Preparation, Implementation, Sustainment (EPIS) implementation framework (20), which highlights key implementation processes and factors across the implementation context. This paper describes the process of developing the action plan and the findings from that process.

\section{Wider context: LifeSpan suicide prevention trial}

This work formed part of a larger Australian suicide prevention trial, LifeSpan (21), delivered by the Black Dog Institute (BDI). LifeSpan is a multi-component suicide prevention approach that involves a range of activities across health, education, and community sectors. The primary aim of the overall LifeSpan trial was to examine whether LifeSpan reduces suicide attempts in the four trial regions relative to rates and temporal trends. The LifeSpan research trial was conducted using a randomised stepped-wedge design across four sites in New South Wales from 2017 to 2020, with a total trial period of two years per site. The final trial site, Murrumbidgee Local Health District, is the subject of the present study. Although the LifeSpan intervention requires implementation of a range of evidence-based activities, including training local health services, the LifeSpan trial was not originally developed as an implementation science initiative. The present study represented a focused implementation evaluation within this broader context. Outcomes from the present study provide insights into the implementation of an evidence-based suicide prevention model and offer invaluable learnings about challenges of conducting implementation research in complex and geographically large settings. 


\section{Methods \\ Setting}

The Murrumbidgee region spans 136,898 square kilometres across southern New South Wales, Australia. The area is serviced by a Local Health District (LHD), which covers a catchment area that is home to approximately 243,228 people in mostly regional and one remote community. This study took place in the Mental Health Drug and Alcohol Service in the Murrumbidgee LHD. This service includes a Mental Health Emergency Consultation Service, a Specialist Community Mental Health Service and Specialist Drug and Alcohol services. Training in CAMS was initially mandatory for Murrumbidgee LHD mental health and drug and alcohol clinicians across these services (approximately 150 staff), however the tailored implementation action plan was targeted primarily at the Specialist Community Mental Health Service. The Specialist Community Mental Health Service comprises six teams from across the Murrumbidgee region. Teams varied widely in their geographic catchment and population covered per full-time equivalent clinician.

\section{Innovation}

Collaborative Assessment and Management of Suicidality (CAMS) is an EBP that provides a flexible therapeutic framework to support a collaborative, suicide-specific approach to assessing and managing suicidality. CAMS offers the opportunity to clinicians and clients to understand the "functional" role of suicidality in the person's life. It uses a structured Suicide Status Form to guide assessment, treatment planning, on-going monitoring of risk, and disposition of care. The preferred use of the Suicide Status Form requires the clinician and client to sit side-by-side and clarify the nature of the person's suicidality through quantitative and qualitative assessments. Within CAMS, a person's 'Suicide Status' (their experience of suicidal thoughts, urges and behaviours and the factors that drive the suicidality) is collaboratively assessed and recorded on a Suicide Status Assessment Form every session. The aim of CAMS is to achieve clinical "resolution" of the person's suicidality and the number of sessions can vary (22). In the present study, CAMS was recommended for use with people above the age of 12 years where suicidality was a key feature of their presentation, and where the person had the cognitive capacity and willingness to engage in the CAMS approach, and the Suicide Status Form was paper-based.

\section{Initial Implementation Strategies}

Training in CAMS in the Murrumbidgee LHD Mental Health Services involved reading the CAMS textbook, completing either a face-to-face workshop or an online course, and participation in at least three team consultation teleconference calls with a CAMS trainer based in the United States. CAMS training was mandatory for all Murrumbidgee LHD mental health clinicians, working across community and MHECS services. Clinicians were trained in CAMS in February 2019 and instructed by executive leadership at the Murrumbidgee LHD to start using CAMS as part of routine practice from the golive date of April 1st 2019. To assist with the sustainment of CAMs, participation in the online course and consultation calls was a requirement for any new team members joining the Murrumbidgee Community Mental Health Drug and Alcohol Service.

Supporting materials produced by the LHD included an initial information sheet on CAMS and six communiques which went out to all clinicians, informing them of updated clinical guidance in line with use of the CAMS approach. Updated guidance included outlining the target client group for CAMS, information on how to use the Suicide Status Form, information on how to integrate the Suicide Status Form with existing electronic medical records system, guidance on how to manage specific clinical issues related to the use of CAMS within the Drug and Alcohol and Mental Health Emergency Consultation Service setting, a tip sheet on how to access the online training, and an information sheet for Visiting Medical Officers. Additionally, an intermediary/purveyor organisation, the Black Dog Institute, provided guidance documents for the consultation calls and a FAQ document on the CAMS approach, which were presented via videoconference to LHD staff. 


\section{Participants}

Participants in this study were Murrumbidgee LHD staff from across Specialist Community Mental Health Drug and Alcohol Service teams. Participants had a range of professional backgrounds, including psychology, social work, occupational therapy, social welfare, and nursing. Specialist areas across the service include child and adolescent, adult, youth, perinatal, older people, consumer advocacy and peer support, drug and alcohol, family and carer, and Aboriginal mental health. Each team comprised of a manager, a generalist clinical leader, and several community mental health clinicians. Generalist clinical leaders for each team were supported by district clinical leaders who provided specialist support across the entire region. One district team within the Specialist Community Mental Health Service was excluded as they had not yet started using CAMS at the time of data collection due to reduced staffing capacity. Participation in the research was voluntary and no reimbursement was offered.

\section{Design}

The present study used a modified version of Lewis and colleagues' methodology for evaluating implementation and generating a 'tailored implementation blueprint' (19). This approach aims to identify barriers and facilitators that serve as determinants of practice and to select implementation strategies to address the identified determinants. The implementation evaluation and tailored action plan development for CAMS in Murrumbidgee LHD comprised the following steps: (1) stakeholder engagement, (2) determinant identification, (3) barrier prioritisation, (4) implementation strategy selection and (5) tailored implementation action plan creation. Authors followed the Standards for Reporting Qualitative Research (SRQR) to report the findings from this study (23).

\section{Step 1: Stakeholder engagement for CAMS implementation in Murrumbidgee LHD}

Before training commenced, a steering committee was established as the decision-making body for the implementation of CAMS in the service, and comprised an LHD executive sponsor and executive lead, and representatives of BDI's research and implementation teams. The steering committee was responsible for making strategic decisions about CAMS training and implementation in the service, including establishing a working group to guide operational implementation. The working group was formed approximately one month after training commenced, with meetings held fortnightly for the first 3 months and then monthly for another 7 months. Membership of the working group consisted of an LHD executive lead, a BDI project manager and a BDI researcher, and 15 standing members from the LHD including team and district managers, clinical leaders, and senior clinicians. The working group assisted in developing the implementation supporting materials, which were distributed to all clinicians. Operational feedback on the use of CAMS from team meetings, training and consultation calls was collated by team managers and fed back to the working group.

\section{Step 2: Determinant identification}

Data collection to identify determinants commenced in June 2019, approximately three months after the initial go-live date to start using CAMS in routine practice.

\section{Determinant data collection}

An online survey was created to quantitatively assess barriers to using CAMS based on the EPIS implementation framework. A link to the survey was emailed to all staff who completed CAMS training $(n=161)$, however only 29 participants (18\%) responded to the survey, with eight of these completing $<50 \%$ of the survey. Due to the low response rate, and after multiple attempts to encourage participation, a pragmatic decision was made to discontinue data 
collection via quantitative survey and instead only use qualitative methods to identify determinants of using CAMS in routine practice.

Semi-structured interviews and focus groups were designed to elicit perceived barriers and facilitators to using CAMS based on the EPIS implementation framework, in addition to self-reported use of CAMS since the go-live date. Community mental health drug and alcohol clinicians, team managers, generalist clinical leaders, and district clinical leaders were all invited to participate in interviews, while only frontline clinicians directly involved in using CAMS in practice were recruited to focus groups, to encourage more open discussion of certain barriers/facilitators, such as leadership. Participants were recruited to partake in the interviews or focus groups through convenience sampling via distribution of study information flyers and/or email invitations by the LHD executive lead. Semi-structured interviews were conducted by three members of the research team (HR, DR, and JL) via teleconference or face-to-face (see Appendix 1 for interview and focus group guides). Focus groups were conducted in person by two members of the research team (HR and JL). Researchers involved in qualitative data collection had experience conducting interviews and moderating group discussions in healthcare settings. Researchers were not employed by the health service so did not have existing working relationships with participants. An adapted version of the interview guide was used to guide the focus group discussion. Two 90-minute focus groups were held at Wagga Wagga Community Mental Health Service and Temora Hospital. Focus groups were limited to ten people to allow all participants to share their perspectives (24).

\section{Determinant data analysis}

De-identified interview and focus group recordings were transcribed using an external transcription service. Data were organised with NVivo Version 12 and analysis guided by Braun \& Clarke's reflexive thematic analysis approach (25). Data analysis involved two members of the research team (DR and JL) immersing themselves in the interview transcripts to familiarise themselves with the data. A complete list of semantic and/or latent codes representing facilitators and barriers to implementing and using CAMS was then developed using an inductive process. Any discrepancies were discussed between researchers (HR, DR, JL, KM, and LM) until consensus was established. Codes were refined and then mapped against the constructs of the EPIS framework.

\section{Step 3: Barrier prioritisation}

The development of an implementation action plan focused on identifying key implementation barriers that could be addressed by tailored implementation strategies and which were likely to have the greatest impact on fidelity to CAMS. From the complete list of barriers, the research team isolated those barriers perceived as amenable to change through local tailored implementation strategies, based on knowledge of the local implementation context including available resourcing. To further prioritise barriers, the research team then contacted CAMS experts in the US, including training facilitators and the intervention creator who have expert knowledge of how CAMS has been implemented and delivered in US healthcare settings. The CAMS experts were asked to rate barriers for perceived impact on fidelity to CAMS from 1 (low impact) to 5 (high impact). Barriers identified as high impact (score of 3 or above) on fidelity were prioritised as determinants for implementation strategy selection.

\section{Step 4: Implementation strategy selection}

Strategies to address the priority determinants were selected by the research team through a matching process (Powell et al., 2015, Waltz et al., 2019). This included team discussion to create a shortlist of feasible strategies to address the prioritised barriers. Eight strategies were identified and modified for relevance to implementing CAMS in the Murrumbidgee LHD (see Appendix 2 for list of strategies).

\section{Step 5: Tailored implementation action plan creation}

Next, LHD staff were emailed a form to determine which of the proposed implementation strategies were most important and feasible in the local context (see Appendix 2 for rating form for tailored implementation strategies). Participants were 
asked to rate the strategies on feasibility and importance using a 5 -point scale $(1=$ low importance/feasibility to $5=$ high importance/feasibility) (Fig. 2). Using this data, the research team created a template implementation action plan containing strategies rated highly (score $\geq 4$ ) for both importance and feasibility (see Appendix 3 for the template tailored implementation action plan).

An online workshop was held with LHD staff to operationalise the proposed strategies, conducted via videoconference and facilitated by a member of the research team $(\mathrm{JL})$. Workshop participants were recruited via an information flyer distributed through email by an LHD executive leader. Leadership and frontline LHD staff were invited to participate in the workshop. Representation from every team was encouraged by the district level manager. Workshop participants were asked to generate goals, actionable steps for implementation, and potential challenges for operationalisation for each strategy. The outcomes of this discussion were collated into a report, which was distributed to LHD team managers and clinical leaders, who invited further review from frontline mental health staff.

Based on a) the number of barriers addressed by each goal and b) the perceived impact on program fidelity as rated by CAMS experts, the research team categorized implementation goals into high, medium or low priority. High priority goals were recommended for immediate implementation whereas medium and low priority goals were suggested to be considered in the longer-term, once high priority goals had been addressed. LHD leadership staff had the authority to determine their own timeframes for implementation. The revised report, including prioritised strategies, was delivered to the LHD as a tailored implementation action plan.

\section{Results}

\section{Identification of determinants: interviews and focus groups}

Ten staff ( $n=2$ community mental health drug and alcohol clinicians and $n=8$ leadership or management staff across six teams) participated in individual interviews. Across two focus groups, seven staff, (all community mental health clinicians from the Temora team) participated at Temora Hospital and 10 staff participated at Wagga Wagga Community Mental Health Service (all community mental health clinicians from the Wagga Wagga team). Due to technical issues, the Wagga Wagga team session was not recorded and analysis was therefore restricted to facilitator notes and materials created during that session. The majority of participants across interviews focus groups were female $(n=22,81 \%)$.

A total of 24 facilitators and 22 barriers to implementing CAMS were identified from interview and focus group data and mapped against domains and constructs of the EPIS framework (Table 1). For almost every construct of the EPIS implementation framework where a facilitator was identified, there was also a barrier identified. The exception was Bridging Factors, which were reported only as facilitators and not barriers. While the tailored implementation action plan focused on barriers, facilitators were used to assist in the operationalisation of implementation strategies where possible. Most barriers related to the EPIS domain of Inner Context ( $n=15$ barriers) followed by Innovation Characteristics ( $n=8$ barriers), with only a few barriers identified for Outer Context ( $n=3$ barriers). No barriers were identified for the Outer Context elements of leadership, service environment/policies, inter-organisational environment and networks, or patient/client advocacy, nor under Bridging Factors. Appendix 4 contains detailed analysis of barriers and facilitators, including exemplar quotes from staff. 
Table 1

Barriers and facilitators to use of CAMS mapped against the EPIS framework

\begin{tabular}{|c|c|c|c|}
\hline Domain & Constructs & Facilitators & Barriers \\
\hline \multirow{11}{*}{$\begin{array}{l}\text { OUTER } \\
\text { CONTEXT }\end{array}$} & \multicolumn{3}{|l|}{ Leadership } \\
\hline & \multicolumn{3}{|l|}{$\begin{array}{l}\text { Service } \\
\text { Environment / } \\
\text { Policies }\end{array}$} \\
\hline & $\begin{array}{l}\text { Funding / } \\
\text { Contracting }\end{array}$ & $\begin{array}{l}\text { - Available funding to provide ongoing } \\
\text { online training/consultation calls }\end{array}$ & $\begin{array}{l}\text { - Difficulties with accessing funds to } \\
\text { provide training }\end{array}$ \\
\hline & \multicolumn{3}{|l|}{$\begin{array}{l}\text { Inter- } \\
\text { organisational } \\
\text { environment } \\
\text { and networks }\end{array}$} \\
\hline & \multirow[t]{6}{*}{$\begin{array}{l}\text { Patient / client } \\
\text { characteristics }\end{array}$} & \multirow[t]{6}{*}{ • Positive response from some clients. } & $\begin{array}{l}\text { - (Large) proportion of clients with } \\
\text { characteristics excluding them from } \\
\text { the use of CAMS / complicating the } \\
\text { use of CAMS }\end{array}$ \\
\hline & & & - Low literacy skills \\
\hline & & & $\begin{array}{l}\text { - Insufficient proficiency of the English } \\
\text { language }\end{array}$ \\
\hline & & & $\begin{array}{l}\text { - Clients with BPD and/or psychotic } \\
\text { symptoms }\end{array}$ \\
\hline & & & - Age \\
\hline & & & - Perceived negative client reactions \\
\hline & $\begin{array}{l}\text { Patient / client } \\
\text { advocacy }\end{array}$ & & \\
\hline \multirow[t]{9}{*}{$\begin{array}{l}\text { INNER } \\
\text { CONTEXT }\end{array}$} & Leadership & $\begin{array}{l}\text { - Team managers/clinical leaders were } \\
\text { approachable and supportive }\end{array}$ & $\begin{array}{l}\text { - Lack of team manager/clinical leader } \\
\text { buy-in* }\end{array}$ \\
\hline & & & - High-level decision making ${ }^{\square}$ \\
\hline & \multirow{3}{*}{$\begin{array}{l}\text { Organisational } \\
\text { characteristics }\end{array}$} & \multirow{3}{*}{$\begin{array}{l}\text { - Open and supportive team cultures } \\
\text { - Teams received training at the same } \\
\text { time }\end{array}$} & - Geographical challenges in $M L H D^{\square}$ \\
\hline & & & - Time-constraints within the service ${ }^{\square}$ \\
\hline & & & $\begin{array}{l}\text { - Recent update to a new client record } \\
\text { system }\end{array}$ \\
\hline & \multirow[t]{2}{*}{$\begin{array}{l}\text { Quality and } \\
\text { fidelity } \\
\text { monitoring / } \\
\text { support }\end{array}$} & $\begin{array}{l}\text { - Attendance at CAMS consultation } \\
\text { calls is monitored } \\
\text { - Discussing CAMS during daily intake } \\
\text { meetings and clinical reviews }\end{array}$ & $\begin{array}{l}\text { - Use of CAMS is not formally } \\
\text { monitored* }\end{array}$ \\
\hline & & $\begin{array}{l}\text { - Development of resources to aid the } \\
\text { use of CAMS }\end{array}$ & \\
\hline & \multirow{2}{*}{$\begin{array}{l}\text { Organisational } \\
\text { staffing } \\
\text { processes }\end{array}$} & \multirow[t]{2}{*}{$\begin{array}{l}\text { - Development of the CAMS Working } \\
\text { Group during implementation phase }\end{array}$} & - Staffing shortages for one team \\
\hline & & & $\begin{array}{l}\text { - Lack of CAMS coordinator across } \\
\text { MLHD }\end{array}$ \\
\hline
\end{tabular}

*Barriers prioritised for implementation strategy selection. ${ }^{\complement}$ Excluded barriers 


\begin{tabular}{|c|c|c|c|}
\hline Domain & Constructs & Facilitators & Barriers \\
\hline & \multirow{4}{*}{$\begin{array}{l}\text { Individual } \\
\text { characteristics }\end{array}$} & - Frontline staff enjoyed training & - Staff hesitance to change* \\
\hline & & $\begin{array}{l}\text { - Positive attitudes towards CAMS with } \\
\text { some clinicians }\end{array}$ & $\begin{array}{l}\text { - Lack of trust in effectiveness of } \\
\text { CAMS in resolving suicidality }\end{array}$ \\
\hline & & $\begin{array}{l}\text { - Good uptake of CAMS by some } \\
\text { teams }\end{array}$ & $\begin{array}{l}\text { - Perceived lack of autonomy when } \\
\text { using CAMS* }\end{array}$ \\
\hline & & $\begin{array}{l}\text { - Good attendance at consultation } \\
\text { calls }\end{array}$ & \\
\hline \multirow[t]{14}{*}{$\begin{array}{l}\text { INNOVATION } \\
\text { FACTORS }\end{array}$} & \multirow{6}{*}{$\begin{array}{l}\text { Innovation fit: } \\
\text { system, } \\
\text { organisation, } \\
\text { provider, patient } \\
\text { / client }\end{array}$} & \multirow[t]{6}{*}{$\begin{array}{l}\text { - CAMS provided a standardised } \\
\text { treatment approach across MLHD }\end{array}$} & $\begin{array}{l}\text { - CAMS approach is perceived as } \\
\text { inconsistent with recovery-based } \\
\text { treatment approach }\end{array}$ \\
\hline & & & - CAMS appropriateness* \\
\hline & & & - Provider skills \\
\hline & & & - Setting \\
\hline & & & - Relevance to AU context \\
\hline & & & $\begin{array}{l}\text { - CAMS forms are not sufficiently } \\
\text { integrated into patient record system }\end{array}$ \\
\hline & \multirow[t]{2}{*}{$\begin{array}{l}\text { Innovation } \\
\text { developers }\end{array}$} & $\begin{array}{l}\text { - Trainer was approachable and } \\
\text { helpful }\end{array}$ & \multirow[t]{2}{*}{ - Absence of local trainers ${ }^{\square}$} \\
\hline & & - Consultation calls were helpful & \\
\hline & \multirow{6}{*}{$\begin{array}{l}\text { Innovation } \\
\text { characteristics }\end{array}$} & - Unique qualities of CAMS framework & - CAMS includes a lot of paperwork \\
\hline & & - Measurement of progress & \multirow{5}{*}{$\begin{array}{l}\text { - Training requirements beyond CAMS } \\
\text { (risk assessment, therapeutic skills)* }^{\star} \\
\text { - CAMS is more time consuming than } \\
\text { treatment as usual }^{\square} \\
\text { - Lack of evidence for use of CAMS } \\
\text { with psychiatric liaison services, ED's, } \\
\text { with indigenous populations and in } \\
\text { Australian context }\end{array}$} \\
\hline & & - Good structure and easy to use & \\
\hline & & - Client focused approach & \\
\hline & & $\begin{array}{l}\text { - Alternative approach to suicide } \\
\text { assessment and management }\end{array}$ & \\
\hline & & - CAMS approach is evidence based & \\
\hline \multirow[t]{2}{*}{$\begin{array}{l}\text { BRIDGING } \\
\text { FACTORS }\end{array}$} & $\begin{array}{l}\text { Community } \\
\text { academic } \\
\text { partnerships }\end{array}$ & $\begin{array}{l}\text { - Evaluation by BDI (providing } \\
\text { academic support throughout the } \\
\text { phases of exploration, implementation } \\
\text { and early sustainment) }\end{array}$ & \\
\hline & $\begin{array}{l}\text { Purveyors / } \\
\text { Intermediaries }\end{array}$ & $\begin{array}{l}\text { - Negotiations with external } \\
\text { stakeholders (CAMS Care available for } \\
\text { ongoing support, i.e. by providing } \\
\text { ongoing consultation calls) }\end{array}$ & \\
\hline
\end{tabular}

Of the 22 barriers identified, 12 were deemed not feasible to change with the available local resources (e.g., LHD systemic factors, amount of CAMS paperwork) and were excluded from strategy development by the research team. A further five barriers were removed based on ratings of the CAMS expert team, as they were deemed to have a limited impact on 
fidelity of CAMS. These included: perceptions of CAMS as inappropriate for a large proportion of clients, negative client reactions to CAMS, lack of trust in CAMS being able to resolve suicidality, perception of CAMS as inconsistent with recovery-based treatment approach, and relevance to Australian context. Appendix 5 contains CAMS experts' ratings of barriers. Six barriers considered feasible to address and likely to have high impact on fidelity were prioritised to be addressed by implementation strategies.

\section{Implementation strategy development}

Eight possible implementation strategies were mapped by the research team to the six barriers. Three strategies were rated by Murrumbidgee LHD staff as the highest for both importance and feasibility (score of 4 or above):

1. Clinical leaders to check in on CAMS at regular staff meetings/during clinical supervision.

2. Allow and communicate flexibility in the use of CAMS for clinicians/teams where CAMS is less appropriate for certain clients; staff participate in consultation calls to troubleshoot issues around 'fit'.

3. Discuss reasons for reluctance to use CAMS/change in practice; provide feedback, information, or education regarding the benefits of change.

Each strategy addressed multiple barriers (Table 2). 
Tailored implementation strategies matched to identified barriers.

\section{Tailored implementation strategy}

1. Clinical leaders to check in on CAMS at regular staff meetings/during clinical supervision.

\section{Barriers targeted by strategy}

Use of CAMS not formally monitored

Lack of team manager/clinical leader buy-in

Staff hesitance to change

Lack of trust in effectiveness of CAMS in resolving suicidality

CAMS appropriateness

a. Provider skills

b. Setting

c. Relevance to Australian context

(Large) proportion of clients with characteristics excluding them from the use of CAMS / complicating the use of CAMS

- Low literacy skills

- Insufficient proficiency of the English language

- Clients with BPD and/or psychotic symptoms

- Age

Perceived lack of autonomy when using CAMS

CAMS appropriateness

a. Provider skills

b. Setting

c. Relevance to Australian context

Staff hesitance to change

Lack of trust in effectiveness of CAMS in resolving suicidality

CAMS appropriateness

a. Provider skills

b. Setting

c. Relevance to Australian context

CAMS approach is perceived as inconsistent with recovery-based treatment approach

Training requirements beyond CAMS (risk assessment, therapeutic skills)

\section{Development of tailored implementation plan: workshops}


To operationalise the strategies, fourteen participants ( $n=11$ female, 79\%) attended an online workshop. All teams from across the LHD Community Mental Health Services were represented, as well as one executive member with decisionmaking power from the LHD Community Mental Health Services. Seven workshop attendees (50\%) had also participated in an interview or focus group.

For each of the three prioritised strategies, workshop participants identified two or three specific goals, with corresponding actionable steps describing practical and realistic to achieve the goals. The tailored implementation plan incorporated the use of existing systems and/or processes as much as possible to minimise the associated workload. For example, using daily intake meetings and clinical review meetings to discuss CAMS-related cases. Foreseeable challenges to putting into action the implementation strategies included limited time, heavy workload, and limitations to clinician's ability to seek supervision regarding CAMS given that some supervisors/clinical leaders may be unfamiliar with CAMS. On request of LHD leadership staff, the research team provided recommendations about the relative priority of each goal (high, medium, low), based on CAMS expert team ratings of the impact on fidelity of CAMS and the number of key barriers addressed by each goal. Across the three prioritised strategies, four goals were deemed high priority, three were deemed medium priority and one was deemed low priority. The full plan outlines the suggested prioritisation of each implementation goal, barriers addressed by each goal, actions to take, parties responsible, how to track progress, and likely operational challenges (Table 3). 
Table 3

CAMS Tailored Implementation Action Plan

\begin{tabular}{|c|c|c|c|c|c|}
\hline Priority & $\begin{array}{l}\text { Implementation } \\
\text { goals }\end{array}$ & Actions to Take & Parties responsible & $\begin{array}{l}\text { Tracking } \\
\text { progress }\end{array}$ & $\begin{array}{l}\text { Operational } \\
\text { challenges }\end{array}$ \\
\hline High & $\begin{array}{l}\text { Address issues } \\
\text { encountered } \\
\text { with using } \\
\text { CAMS }\end{array}$ & $\begin{array}{l}\text { Team Clinical Leaders } \\
\text { to prioritise discussing } \\
\text { and tracking progress } \\
\text { of CAMS use with } \\
\text { frontline staff during } \\
\text { existing meetings (e.g. } \\
\text { clinical review } \\
\text { meetings, daily intake } \\
\text { meetings, Clinical } \\
\text { Review and Support } \\
\text { Process known as } \\
\text { 'CRASP, Clinical } \\
\text { Supervision'). During } \\
\text { these meetings, the } \\
\text { team can discuss: } \\
\text { - Caseload } \\
\text { - Complex } \\
\text { presentations } \\
\text { - How they are } \\
\text { implementing CAMS } \\
\text { and their experiences } \\
\text { with it (including } \\
\text { success stories and } \\
\text { challenges along the } \\
\text { way). }\end{array}$ & $\begin{array}{l}\text { Team Clinical Leaders } \\
\text { Frontline staff }\end{array}$ & $\begin{array}{l}\text { Meeting } \\
\text { minutes can } \\
\text { be added to a } \\
\text { CAMS } \\
\text { spreadsheet } \\
\text { on } \\
\text { SharePoint. } \\
\text { This } \\
\text { spreadsheet } \\
\text { will be } \\
\text { accessible by } \\
\text { any team } \\
\text { across the } \\
\text { Murrumbidgee } \\
\text { district. }\end{array}$ & $\begin{array}{l}\text { Clinical leaders } \\
\text { have very } \\
\text { limited time to } \\
\text { implement new } \\
\text { procedures, so } \\
\text { changes need } \\
\text { to be } \\
\text { integrated with } \\
\text { processes that } \\
\text { are already in } \\
\text { place. } \\
\text { Clinical leaders } \\
\text { who do not feel } \\
\text { comfortable } \\
\text { with using } \\
\text { CAMS } \\
\text { themselves } \\
\text { may find it } \\
\text { challenging to } \\
\text { address some } \\
\text { of the issues } \\
\text { raised. }\end{array}$ \\
\hline High & $\begin{array}{l}\text { Create a } \\
\text { comprehensive } \\
\text { resource for } \\
\text { CAMS that is } \\
\text { continually } \\
\text { updated }\end{array}$ & $\begin{array}{l}\text { Create spreadsheet on } \\
\text { SharePoint to record } \\
\text { and share notes on: } \\
\text { - Meeting minutes } \\
\text { relevant to CAMS } \\
\text { - Tally of clients CAMS } \\
\text { have been used with } \\
\text { - Audit of number of } \\
\text { CAMS sheets used, } \\
\text { how far frontline staff } \\
\text { got through with it, and } \\
\text { whether they } \\
\text { completed CAMS } \\
\text { This document will be } \\
\text { accessible by all teams } \\
\text { including the District } \\
\text { Clinical Leader. Team } \\
\text { Clinical Leaders will be } \\
\text { responsible for } \\
\text { updating the } \\
\text { spreadsheet and } \\
\text { frontline staff are } \\
\text { responsible for keeping } \\
\text { track of this } \\
\text { information. }\end{array}$ & $\begin{array}{l}\text { District Clinical Leader } \\
\text { Team Clinical Leader } \\
\text { Frontline staff }\end{array}$ & $\begin{array}{l}\text { The District } \\
\text { Clinical } \\
\text { Leader will be } \\
\text { responsible } \\
\text { for monitoring } \\
\text { the } \\
\text { progression of } \\
\text { this } \\
\text { spreadsheet, } \\
\text { ensuring that } \\
\text { each team in } \\
\text { the district are } \\
\text { providing } \\
\text { ongoing } \\
\text { updates. }\end{array}$ & $\begin{array}{l}\text { Maintaining } \\
\text { the } \\
\text { spreadsheet } \\
\text { would add } \\
\text { onto workload. }\end{array}$ \\
\hline
\end{tabular}




\begin{tabular}{|c|c|c|c|c|c|c|c|}
\hline \multicolumn{8}{|c|}{ Strategy 1: Clinical leaders check in on CAMS at regular staff meetings/during clinical supervision. } \\
\hline Medium & $\begin{array}{l}\text { Increase } \\
\text { visibility of } \\
\text { CAMS }\end{array}$ & \multicolumn{2}{|c|}{$\begin{array}{l}\text { Add CAMS to a } \\
\text { desktop checklist. E.g. } \\
\text { a drop-down box on } \\
\text { electronic records for } \\
\text { frontline staff to mark } \\
\text { whether CAMS has } \\
\text { been completed. }\end{array}$} & \multicolumn{2}{|c|}{ 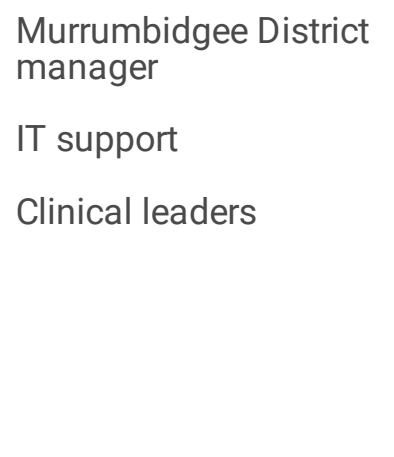 } & $\begin{array}{l}\text { Use of CAMS } \\
\text { can be } \\
\text { audited during } \\
\text { daily risk } \\
\text { register. }\end{array}$ & \\
\hline \multicolumn{8}{|c|}{$\begin{array}{l}\text { Strategy 2: Allow and communicate flexibility in use of CAMS for clinicians/teams where CAMS is less appropriate. } \\
\text { Participate in consultation calls to troubleshoot issues around 'fit'. }\end{array}$} \\
\hline Priority & $\begin{array}{l}\text { Implementation } \\
\text { goals }\end{array}$ & $\begin{array}{l}\text { Actions to } \\
\text { Take }\end{array}$ & $\begin{array}{l}\text { Partie } \\
\text { respol }\end{array}$ & & Tracking progr & & $\begin{array}{l}\text { Operational } \\
\text { challenges }\end{array}$ \\
\hline High & $\begin{array}{l}\text { Sustain } \\
\text { consultation } \\
\text { calls }\end{array}$ & $\begin{array}{l}\text { Negotiate } \\
\text { funding for } \\
\text { ongoing } \\
\text { consultation } \\
\text { calls with } \\
\text { CAMS-Care. } \\
\text { Funding for } \\
\text { this has been } \\
\text { agreed upon } \\
\text { at the } \\
\text { executive } \\
\text { level and is } \\
\text { embedded in } \\
\text { MLHD budget } \\
\text { for } \\
\text { professional } \\
\text { development. } \\
\text { Discuss how } \\
\text { an internal } \\
\text { process for } \\
\text { consultation } \\
\text { calls may be } \\
\text { established. } \\
\text { E.g. Clinical } \\
\text { leaders may } \\
\text { be able to } \\
\text { provide } \\
\text { internal } \\
\text { consultations. }\end{array}$ & $\begin{array}{l}\text { Murru } \\
\text { Distric } \\
\text { mana }\end{array}$ & $\begin{array}{l}\text { ibidgee } \\
\text { ers }\end{array}$ & $\begin{array}{l}\text { Murrumbidgee } \\
\text { managers to u } \\
\text { availability of c } \\
\text { calls. }\end{array}$ & $\begin{array}{l}\text { istrict } \\
\text { late teams on } \\
\text { nsultation }\end{array}$ & $\begin{array}{l}\text { Budget } \\
\text { restrictions } \\
\text { may limit } \\
\text { provisions for } \\
\text { ongoing } \\
\text { consultation } \\
\text { calls with } \\
\text { CAMS. }\end{array}$ \\
\hline
\end{tabular}




\begin{tabular}{|c|c|c|c|c|c|}
\hline \multicolumn{6}{|c|}{ Strategy 1: Clinical leaders check in on CAMS at regular staff meetings/during clinical supervision. } \\
\hline Medium & $\begin{array}{l}\text { Identify } \\
\text { alternative } \\
\text { treatment } \\
\text { approaches for } \\
\text { clients where } \\
\text { CAMS has been } \\
\text { deemed } \\
\text { inappropriate }\end{array}$ & $\begin{array}{l}\text { Discuss } \\
\text { during clinical } \\
\text { review } \\
\text { meetings if } \\
\text { CAMS model } \\
\text { is appropriate } \\
\text { for their } \\
\text { clients and } \\
\text { discuss } \\
\text { alternatives if } \\
\text { CAMS does } \\
\text { not fit. }\end{array}$ & $\begin{array}{l}\text { Team and } \\
\text { District } \\
\text { Clinical } \\
\text { Leaders } \\
\text { Frontline staff }\end{array}$ & $\begin{array}{l}\text { These notes could be added to } \\
\text { the CAMS spreadsheet on } \\
\text { SharePoint. }\end{array}$ & $\begin{array}{l}\text { If supervisors } \\
\text { aren't aware of } \\
\text { or comfortable } \\
\text { with CAMS as } \\
\text { a strategy, } \\
\text { clinicians may } \\
\text { not have an } \\
\text { avenue to } \\
\text { discuss issues. } \\
\text { Limitations } \\
\text { with time- } \\
\text { people would } \\
\text { need to } \\
\text { prioritise } \\
\text { problem } \\
\text { solving issues } \\
\text { around using } \\
\text { CAMS }\end{array}$ \\
\hline Low & $\begin{array}{l}\text { Maximise the } \\
\text { utility of } \\
\text { consultation } \\
\text { calls with } \\
\text { CAMS-Care }\end{array}$ & $\begin{array}{l}\text { Discuss with } \\
\text { CAMS-Care } \\
\text { about } \\
\text { providing an } \\
\text { agenda/list of } \\
\text { topics for the } \\
\text { consultation } \\
\text { calls. Suggest } \\
\text { that these } \\
\text { calls can also } \\
\text { be used to } \\
\text { provide } \\
\text { education on } \\
\text { an aspect of } \\
\text { the model. } \\
\text { Consultation } \\
\text { calls to be } \\
\text { opened to all } \\
\text { staff } \\
\text { regardless of } \\
\text { teams so that } \\
\text { attendees } \\
\text { may benefit } \\
\text { from sharing } \\
\text { experiences. } \\
\text { Frontline staff } \\
\text { to attend } \\
\text { consultation } \\
\text { calls. Pair } \\
\text { teams up to } \\
\text { join } \\
\text { consultation } \\
\text { calls to share } \\
\text { knowledge } \\
\text { and discuss } \\
\text { cases. } \\
\text { Set up a } \\
\text { reminder for } \\
\text { upcoming } \\
\text { calls. }\end{array}$ & $\begin{array}{l}\text { CAMS-Care } \\
\text { District } \\
\text { Clinical } \\
\text { Leader } \\
\text { Frontline staff } \\
\text { Murrumbidgee } \\
\text { LHD } \\
\text { Coordinator }\end{array}$ & $\begin{array}{l}\text { Continue to monitor attendance } \\
\text { to consultation calls using the } \\
\text { spreadsheet that has been } \\
\text { created and record on My } \\
\text { Health Learning. }\end{array}$ & $\begin{array}{l}\text { Potential } \\
\text { technical } \\
\text { difficulties with } \\
\text { joining } \\
\text { consultation } \\
\text { calls with other } \\
\text { teams. }\end{array}$ \\
\hline
\end{tabular}




\begin{tabular}{|c|c|c|c|c|c|}
\hline Priority & $\begin{array}{l}\text { Implementation } \\
\text { goals }\end{array}$ & $\begin{array}{l}\text { Actions to } \\
\text { Take }\end{array}$ & $\begin{array}{l}\text { Parties } \\
\text { responsible }\end{array}$ & Tracking progress & $\begin{array}{l}\text { Operational } \\
\text { challenges }\end{array}$ \\
\hline High & $\begin{array}{l}\text { Upskill staff to } \\
\text { ensure they are } \\
\text { equipped to } \\
\text { implement } \\
\text { CAMS }\end{array}$ & $\begin{array}{l}\text { Ensure that } \\
\text { staff have } \\
\text { completed all } \\
\text { components } \\
\text { of the CAMS } \\
\text { training. This } \\
\text { can either be } \\
\text { the } 1 \text { day of } \\
\text { face-to-face } \\
\text { training or the } \\
\text { online training } \\
\text { course. Staff } \\
\text { must also } \\
\text { have read the } \\
\text { CAMS } \\
\text { textbook to } \\
\text { complete the } \\
\text { training and } \\
\text { attend a } \\
\text { minimum of } 3 \\
\text { CAMS } \\
\text { consultation } \\
\text { calls. } \\
\text { Provide } \\
\text { opportunities } \\
\text { for staff to } \\
\text { attend further } \\
\text { training or } \\
\text { refresher } \\
\text { workshops for } \\
\text { CAMS. } \\
\text { Additional } \\
\text { training could } \\
\text { focus on } \\
\text { specific parts } \\
\text { of the model. } \\
\text { Schedule time } \\
\text { for teams to } \\
\text { practice using } \\
\text { CAMS with } \\
\text { each other. } \\
\text { This could } \\
\text { occur on days } \\
\text { when staff are } \\
\text { gathered in } \\
\text { the office. }\end{array}$ & $\begin{array}{l}\text { Murrumbidgee } \\
\text { District } \\
\text { managers } \\
\text { Team Clinical } \\
\text { Leaders } \\
\text { Frontline staff }\end{array}$ & $\begin{array}{l}\text { Completion of additional } \\
\text { training can be noted in the } \\
\text { CAMS spreadsheet on } \\
\text { SharePoint or recorded on My } \\
\text { Health Learning. } \\
\text { Team practice can be recorded } \\
\text { on the CAMS spreadsheet on } \\
\text { SharePoint. }\end{array}$ & $\begin{array}{l}\text { Limited time, } \\
\text { heavy } \\
\text { workload, } \\
\text { constraints on } \\
\text { human and } \\
\text { service } \\
\text { resources } \\
\text { could limit the } \\
\text { capacity to run } \\
\text { additional } \\
\text { training. } \\
\text { Team practice } \\
\text { with CAMS } \\
\text { would have to } \\
\text { be added as an } \\
\text { additional } \\
\text { meeting which } \\
\text { would take up } \\
\text { time. } \\
\text { Geography - } \\
\text { trainings are } \\
\text { predominantly } \\
\text { held in Wagga. } \\
\text { Localised } \\
\text { trainings would } \\
\text { be beneficial. }\end{array}$ \\
\hline
\end{tabular}




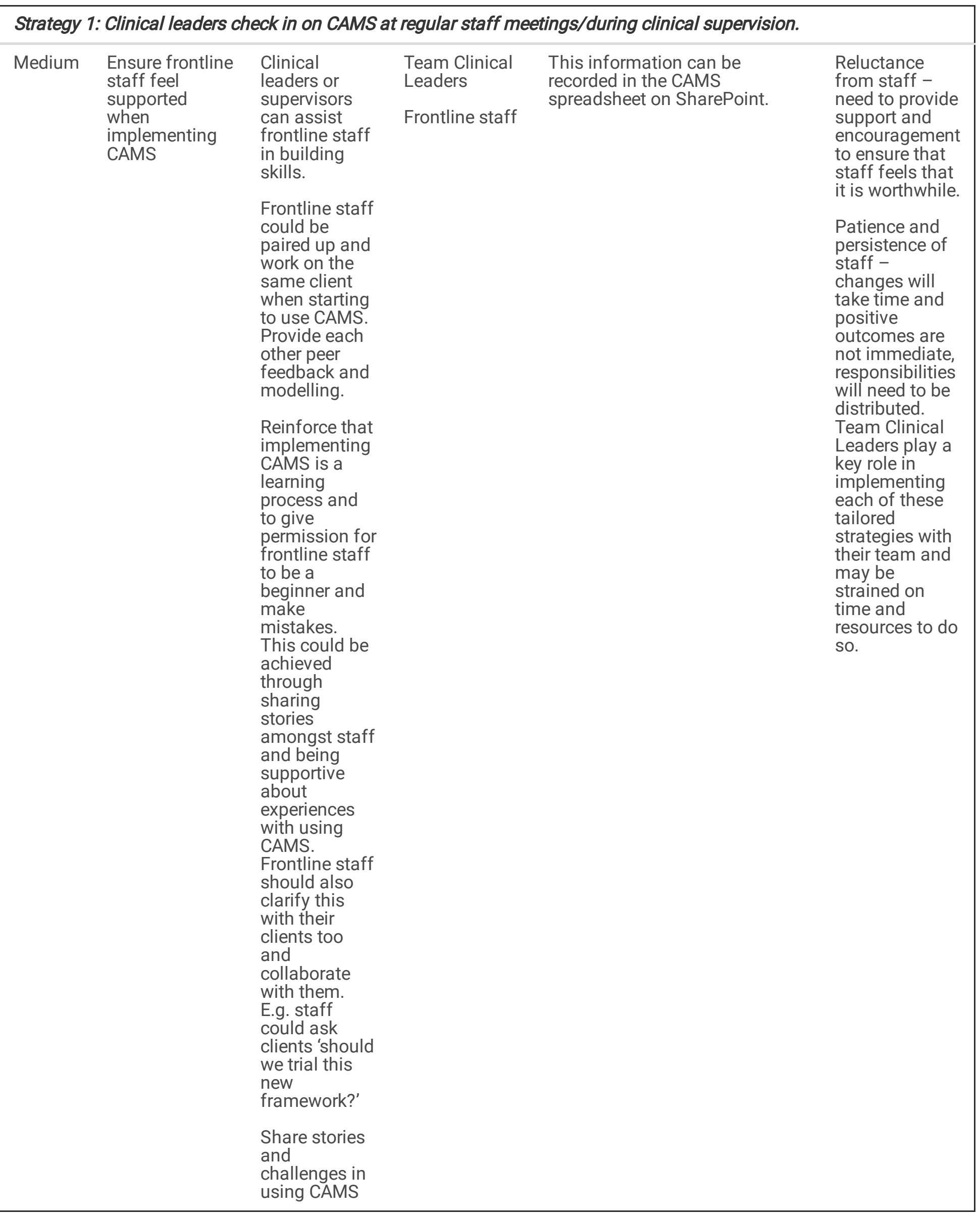


This study details the process for developing a tailored implementation plan to support the implementation and sustainment of a new clinical approach to managing suicidality in the setting of an Australian public mental health service. This study provides novel insights into implementation facilitators and barriers to using a clinical suicide prevention EBP within an Australian mental health service. It also provides a case study of the collaborative development of a tailored implementation plan to support ongoing sustainment of the EBP after research support ceases.

By using the EPIS framework, we were able to systematically identify a range of implementation barriers. Most identified barriers related to the EPIS domain of Inner Context, followed by Innovation Characteristics, with only a few barriers identified for Outer Context and none related to Bridging Factors. This pattern of results likely reflected participants' primary focus on overcoming immediate barriers to using CAMS in routine care, associated mainly with internal processes and elements of the model itself such as associated paperwork. Prioritised barriers and associated strategies related to Inner Context align with previous studies, indicating that strong internal processes are needed to support the sustained use of training (26). For example, developing a positive implementation climate whereby managers and team leaders communicate the value of CAMS, conduct regular progress reviews and supervision in using CAMS, and establish structures to review fidelity (27). Another study, conducted in US community mental health settings, similarly found that implementation success correlated with active leadership, where barriers were addressed as they arise and workflow was redesigned for changes in practice (28). The relatively low focus on Outer Context and Bridging Factors in the present study also likely reflects the profile of participants, who were predominantly frontline workers whose primary role is to care for clients, rather than consider broader systemic and network factors that may have a more indirect effect on care delivery. By combining research expertise with local service and care delivery expertise, the present study was able to identify implementation strategies that were perceived as important for fidelity as well as feasible to implement.

Lewis and colleagues' (2018) methodology provided a structured, collaborative way to engage stakeholders to integrate both empirical research and practice expertise. The large geographic areas covered by stakeholders in the present study (LHD coverage of $136,898 \mathrm{~km}^{2}$, which is more than the total area of Greece) and the CAMS trainers based in the United States meant that it was cost-prohibitive to arrange in-person meetings for all project activities. By using digital solutions to collaboration (via email, phone, and videoconferencing), the present study adds to growing evidence for the remote development of tailored implementation strategies and plans that are both evidence- and practice-informed (29). This methodology may therefore be useful in guiding future implementation efforts, with appropriate modifications based on the innovation, setting and stage of implementation.

The present study modified Lewis et al.'s (2018) implementation blueprint methodology in two main ways. First, instead of creating a plan prior to implementation to include preparation, implementation and sustainment phases, the present study identified facilitators and barriers during the implementation phase. Although this meant a less rigorous approach to preparation, it had the advantage of exploring facilitators and barriers to implementation based on participants' actual experiences of using a new approach to care rather than their anticipated experiences. Second, rather than using a mixedmethods approach to action planning, the present study used only qualitative data due to low response rates to the quantitative survey. While this meant less data was collected, interviews and focus groups were able to provide a rich and nuanced understanding of barriers.

Despite the known challenges of implementing new models of care into health care settings and Australia's focus on national mental health and suicide prevention strategies, there is surprisingly little research on implementation of suicide prevention programs in Australian care settings. Findings suggest that mental health organisations seeking to implement new programs or approaches to care should ensure that internal organisational structures and processes are adequately prepared, and that the EBP being implemented is appropriate for the local context in terms of client profile and staff skills. Strategies should ideally be integrated with existing systems and procedures to avoid adding burden to an already heavy workload (e.g., using existing team meetings as a forum to discuss issues and experiences). Having a clear plan for 
developing implementation strategies, which includes contingency procedures, is key to ensuring rigorous implementation efforts are sustained in practice.

There are several limitations to the present study. Firstly, not all identified barriers were amenable or feasible to change. This was particularly the case for outer-context and structural barriers, for example, funding, staff shortages, integration of CAMS with existing record keeping systems, and geographical challenges of providing care across vast rural and remote settings. Although some of these barriers were addressed by the service outside of formal action planning, several of these challenges would have required significant resourcing to overcome and were therefore not feasible to address in the present study. It should be noted that some of these barriers are also likely to be challenges for mental health care delivery in general for this region, rather than being specific to CAMS. Second, data collection identified both facilitators and barriers to implementation, however, implementation strategies focused on barriers. Facilitators were used to aid overcoming barriers in a few cases. In future studies, facilitators might be considered in a more in-depth manner and used to assist in the selection of implementation strategies. Finally, the extent to which the implementation strategies were applied or their effectiveness on outcomes is not yet known. The initial research design included follow up interviews to investigate progress on the proposed strategies, however these plans were delayed as bushfires in New South Wales in late 2019 and early 2020 reduced participants' capacity to participate in this research, which was further complicated by the COVID-19 pandemic. These real-world unanticipated events are a reality of applied implementation research. It would be valuable to conduct further research in the Murrumbidgee LHD to both evaluate the tailored implementation plan and to understand how the dynamic outer context factors have influenced implementation and adaptation of the CAMS intervention, particularly given the likely impact of both bushfires and the COVID-19 pandemic on mental health.

\section{Conclusion}

The present study offers an example of a collaborative approach to tailoring strategies for implementation of a suicide prevention intervention in a geographically large and varied mental health setting. Findings from the current study reflect the difficulties of both implementing new approaches to care and evaluating the process on a large scale and in a complex, dynamic environment. Future studies should ensure time and resources allow for participants to effectively engage with evaluation strategies and ongoing implementation activities. Further collaborative implementation research

focused on suicide prevention in real-world settings will be invaluable for building understandings of how best to sustain evidence-based practice in this space.

\section{List Of Abbreviations}

BDI: Black Dog Institute

CAMS: Collaborative Assessment and Management of Suicidality

EBP: Evidence-Based Practice

ED: Emergency Department

EPIS: Exploration, Preparation, Implementation, Sustainment

MHECS: Mental Health Emergency Consultation Service

LHD: Local Health District

\section{Declarations}

Page 19/24 
Ethics approval and consent to participate

This study was approved under the LifeSpan suicide prevention trial by the Hunter New England Human Research Ethics Committee.

\section{Consent for publication}

Not applicable

\section{Availability of data and materials}

The datasets analysed for the current study available from the corresponding author on reasonable request. Study materials including interview and focus group guides, scoring sheets and workshop worksheets are available as Appendices.

\section{Competing interests}

Authors declare they have no competing interests.

\section{Funding}

Funding for the roles of IZ, DR, HR, JL, KM, LM, ES was supported by a AU\$14.76 million grant from the Paul Ramsay Foundation. IZ's position at Orygen, Centre for Youth Mental Health, University of Melbourne, is supported by an AU\$4.3 million grant from the Australian Government Department of Health. KMc's MH-READ position is supported by funding from the Burdekin Suicide Prevention Program, administered by Hunter New England Mental Health Service; KMc is the recipient of a Suicide Prevention Australia PhD scholarship, made available through a partnership with Regional Australia Bank. Design of the study and collection, analysis, and interpretation of data and writing of the manuscript were conducted independent of funding bodies.

\section{Authors' contributions}

IZ was responsible for overall study design, initial stakeholder engagement and coordination, overseeing data collection and analysis, and designing, drafting, and revising the manuscript. DR assisted with the development of the interview and focus group questions, was involved in data collection and qualitative analysis of interview and focus group data, and was involved in drafting and revising the manuscript. LM contributed to the coordination of implementation and evaluation activities, designing the quantitative survey, qualitative data analysis, and was involved in drafting and revising the manuscript. ES led stakeholder engagement, advised on and supported local implementation of the intervention, assisted with data collection and coordination of workshops, and was involved in drafting and revising the manuscript. $\mathrm{KM}$ contributed to the design of quantitative and qualitative data collection and analysis methods, and was involved in drafting and revising the manuscript. KMc the manuscript. JL was responsible for the development of research tools, stakeholder coordination, qualitative data collection and analysis, facilitation of the online workshop, and drafting and revising the manuscript. HR contributed to the development of research tools, qualitative data collection and analysis, as well as drafting and revising the manuscript. FS advised on overall study design and implementation approach, and contributed to revising the manuscript. MT provided guidance in planning and overall supervision of the work. JM provided guidance on overall study design, use of the EPIS framework in analysis, and significantly revised the manuscript. All authors have read and approved the final manuscript.

\section{Acknowledgements}

Authors acknowledge the input of leaders and frontline staff at the Murrumbidgee Local Health District, who played a key role in this project as participants and implementers; the CAMS-Care team, who were responsible for delivering training 
and providing expert consultation as part of the evaluation; the LifeSpan Murrumbidgee LifeSpan Coordinators, who supported this study as part of the broader LifeSpan trial and connected researchers with leaders at the Local Health District; the LifeSpan Implementation Team, who actively supported implementation and research processes throughout all stages of implementation and evaluation; the LifeSpan Data Team, who supported quantitative data collection; $\mathrm{Dr}$ Natalie Stefanic, who contributed to study planning and stakeholder engagement early in the project; and Dr Cara Lewis, who provided expert consultation in the early stages of study design.

\section{References}

1. Australian Bureau of Statistics. Causes of Death, Australia 2018 [Available from:

https://www.abs.gov.au/statistics/health/causes-death/causes-death-australia/2018.

2. Commonwealth of Australia. The Fifth National Mental Health and Suicide Prevention Plan. Canberra: Department of Health; 2017.

3. National Suicide Prevention Project Reference Group. National suicide prevention implementation strategy 20202025: Working together to save lives. 2019.

4. van der Feltz-Cornelis CM, Sarchiapone M, Postuvan V, Volker D, Roskar S, Grum AT, et al. Best practice elements of multilevel suicide prevention strategies: a review of systematic reviews. Crisis. 2011;32(6):319-33.

5. Jobes DA. The Collaborative Assessment and Management of Suicidality (CAMS): An Evolving Evidence-Based Clinical Approach to Suicidal Risk. Suicide Life-Threatening Behavior. 2012;42(6):640-53.

6. Comtois KA, Jobes DA, Atkins SSOC, Janis DC, C K. EC, et al. Collaborative assessment and management of suicidality (CAMS): feasibility trial for next-day appointment services. Depress Anxiety. 2011;28(11):963-72.

7. Ellis TE, Rufino KA, Allen JG. A controlled comparison trial of the Collaborative Assessment and Management of Suicidality (CAMS) in an inpatient setting: Outcomes at discharge and six-month follow-up. Psychiatry research. 2017;249:252-60.

8. Jobes DA, Comtois KA, Gutierrez PM, Brenner LA, Huh D, Chalker SA, et al. A Randomized Controlled Trial of the Collaborative Assessment and Management of Suicidality versus Enhanced Care as Usual With Suicidal Soldiers. Psychiatry. 2017;80(4):339-56.

9. Jobes DA, Wong SA, Conrad AK, Drozd JF, Neal-Walden T. The collaborative assessment and management of suicidality versus treatment as usual: a retrospective study with suicidal outpatients. Suicide Life-Threatening Behav. 2005;35(5):483-97.

10. Nielsen AC, Alberdi F, Rosenbaum B. Collaborative assessment and management of suicidality method shows effect. Danish medical bulletin. 2011;58(8):A4300.

11. Pistorello J, Jobes DA, Gallop R, Compton SN, Locey NS, Au JS, et al. A Randomized Controlled Trial of the Collaborative Assessment and Management of Suicidality (CAMS) Versus Treatment as Usual (TAU) for Suicidal College Students. Arch Suicide Res. 2020:1-25.

12. Ryberg W, Zahl PH, Diep LM, Landrø NI, Fosse R. Managing suicidality within specialized care: A randomized controlled trial. J Affect Disord. 2019;249:112-20.

13. Gutierrez PM, O'Connor SS, Johnson LL, Dwyer M, Mund NE, Jobes DA. Training Clinicians to Provide Collaborative Assessment and Management of Suicidality - Group (CAMS-G) for Veterans. Military Behavioral Health. 2020;8(1):21-32.

14. Baker R, Camosso-Stefinovic J, Gillies C, Shaw EJ, Cheater F, Flottorp S, et al. Tailored interventions to address determinants of practice. Cochrane Database of Systematic Reviews. 2015(4).

15. Aarons GA, Hurlburt M, Horwitz SM. Advancing a conceptual model of evidence-based practice implementation in public service sectors. Adm Policy Ment Health. 2011;38(1):4-23. 
16. Powell BJ, Beidas RS, Lewis CC, Aarons GA, McMillen JC, Proctor EK, et al. Methods to Improve the Selection and Tailoring of Implementation Strategies. J Behav Health Serv Res. 2017;44(2):177-94.

17. Joosen MCW, van Beurden KM, Rebergen DS, Loo MAJM, Terluin B, van Weeghel J, et al. Effectiveness of a tailored implementation strategy to improve adherence to a guideline on mental health problems in occupational health care. BMC Health Services Research. 2019;19(1):281.

18. Zbukvic IC, Mok K, McGillivray L, Chen NA, Shand FL, Torok MH. Short report: Understanding the process of multilevel suicide prevention research trials. Evaluation Program Planning. 2020;82:101850.

19. Lewis CC, Scott K, Marriott BR. A methodology for generating a tailored implementation blueprint: an exemplar from a youth residential setting. Implement Sci. 2018;13(1):68.

20. Moullin JC, Dickson KS, Stadnick NA, Rabin B, Aarons GA. Systematic review of the Exploration, Preparation, Implementation, Sustainment (EPIS) framework. Implementation Science. 2019;14(1):1.

21. Shand F, Torok M, Cockayne N, Batterham PJ, Calear AL, Mackinnon A, et al. Protocol for a stepped-wedge, cluster randomized controlled trial of the LifeSpan suicide prevention trial in four communities in New South Wales, Australia. Trials. 2020;21(1):332.

22. Jobes DA, Jacoby AM, Cimbolic P, Hustead LAT. Assessment and treatment of suicidal clients in a university counseling center. Journal of Counseling Psychology. 1997;44(4):368-77.

23. O’Brien BC, Harris IB, Beckman TJ, Reed DA, Cook DA. Standards for Reporting Qualitative Research: A Synthesis of Recommendations. Academic Medicine. 2014;89(9).

24. Fern EF. The Use of Focus Groups for Idea Generation: The Effects of Group Size, Acquaintanceship, and Moderator on Response Quantity and Quality. J Mark Res. 1982;19(1):1-13.

25. Braun V, Clarke V. Using thematic analysis in psychology. Qualitative Research in Psychology. 2006;3(2):77-101.

26. Deane FP, Crowe TP, King R, Kavanagh DJ, Oades LG. Challenges in implementing evidence-based practice into mental health services. Aust Health Rev. 2006;30(3):305-9.

27. Aarons GA, Ehrhart MG, Moullin JC, Torres EM, Green AE. Testing the leadership and organizational change for implementation (LOCI) intervention in substance abuse treatment: a cluster randomized trial study protocol. Implementation Science. 2017;12(1):29.

28. Torrey WC, Bond GR, McHugo GJ, Swain K. Evidence-based practice implementation in community mental health settings: the relative importance of key domains of implementation activity. Adm Policy Ment Health. 2012;39(5):353-64.

29. Kwok EYL, Moodie STF, Cunningham BJ, Oram Cardy JE. Selecting and tailoring implementation interventions: a concept mapping approach. BMC Health Serv Res. 2020;20(1):385.

\section{Figures}




\begin{tabular}{|c|c|c|c|c|}
\hline $\begin{array}{l}\text { Step 1: } \\
\text { Stakeholder } \\
\text { engagement }\end{array}$ & $\begin{array}{l}\text { Step 2: } \\
\text { Determinant } \\
\text { identification }\end{array}$ & $\begin{array}{l}\text { Step 3: } \\
\text { Barrier } \\
\text { prioritisation }\end{array}$ & $\begin{array}{l}\text { Step 4: } \\
\text { Implementation } \\
\text { strategy selection }\end{array}$ & $\begin{array}{l}\text { Step 5: } \\
\text { Tailored implementation } \\
\text { action plan creation }\end{array}$ \\
\hline $\begin{array}{ll}\text { - } & \text { Steering } \\
\text { Committee } \\
\text { established } \\
\text { Working Group } \\
\text { established }\end{array}$ & $\begin{array}{ll}\text { - } & \text { Survey } \\
\text { - } & \text { Interviews } \\
\text { - } & \text { Focus groups }\end{array}$ & $\begin{array}{l}\text { Experts rated } \\
\text { barriers based on } \\
\text { perceived impact } \\
\text { on fidelity }\end{array}$ & $\begin{array}{l}\text { Matching potential } \\
\text { implementation } \\
\text { strategies to high } \\
\text { priority barriers }\end{array}$ & $\begin{array}{l}\text { Service staff rated } \\
\text { strategies based on } \\
\text { feasibility and } \\
\text { importance } \\
\text { - Workshop with service } \\
\text { staff to operationalize } \\
\text { implementation } \\
\text { strategies }\end{array}$ \\
\hline $\begin{array}{l}\text { Implementation } \\
\text { supporting } \\
\text { materials }\end{array}$ & $\begin{array}{l}\text { Complete list of } \\
\text { barriers and } \\
\text { facilitators to } \\
\text { implementation }\end{array}$ & $\begin{array}{l}\text { Prioritized } \\
\text { barriers }\end{array}$ & $\begin{array}{l}\text { Shortlist of } \\
\text { implementation } \\
\text { strategies }\end{array}$ & $\begin{array}{l}\text { - Tailored } \\
\text { implementation action } \\
\text { plan }\end{array}$ \\
\hline
\end{tabular}

\section{Figure 1}

Steps taken to develop a tailored implementation action plan.

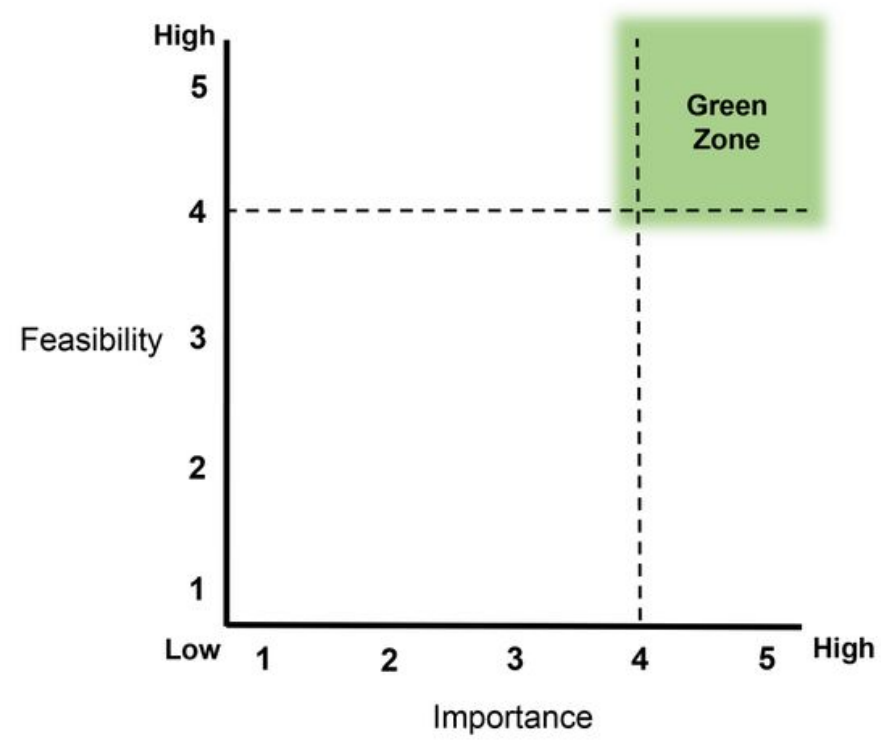

Figure 2 
'Green zone' implementation strategies rated highly on feasibility and importance were included in action planning.

\section{Supplementary Files}

This is a list of supplementary files associated with this preprint. Click to download.

- CAMSAppendices.docx

- CAMSSRQRChecklist.pdf 